\title{
Final Transitions: Family Caregiving at the End of Life
}

\author{
DEBORAH P. WALDROP, M.S.W., Ph.D., ${ }^{1}$ BETTY J. KRAMER, MSW, Ph.D., ${ }^{2}$ \\ JUDITH A. SKRETNY, M.A., ${ }^{3}$ ROBERT A. MILCH, M.D., ${ }^{3}$ and WILLIAM FINN, M.B.A. ${ }^{3}$
}

\begin{abstract}
Background: This study aimed to understand how caregivers make the transition to end-stage caregiving and to illuminate its unique aspects using a stress process model.

Methods: Qualitative in-depth interviews were conducted with 74 caregivers of a family member who had been receiving hospice care for at least 2 weeks. Interviews were tape recorded, transcribed, and coded for emergent themes using constant comparative analysis.

Results: End-stage caregiving was characterized in the sample as (1) comprehension of terminality (the interrelationship of information, physical and cognitive decline, and personality change and role losses), (2) near-acute care, (3) executive functions, and (4) final decision making. The comprehension of terminality emerged from three interrelated experiences: receiving and assimilating concrete information about the illness, observing the progression of the disease, and observing the personality change and role loss. The primary stressors (unique end-stage caregiving tasks) were providing near-acute care, assuming an executive function, and beginning and final decision making. The secondary stressors were family role conflict, work conflict, and financial strain. Resources, such as intrinsic and extrinsic religious and faith practices and social support, were identified. Negative outcomes included intense emotional responses, and positive outcomes included heightened development of meaning making.

Conclusion: The findings suggest that palliative care professionals have important opportunities to provide information and support to family caregivers during the final stages of the patient's terminal illness.
\end{abstract}

\section{INTRODUCTION}

O VER THE PAST THREE DECADES, increasing numbers of family members have been providing care at home for loved ones who are chronically ill or disabled. Presently, nearly one in four households provides care for someone older than 50 years of age who needs daily assistance; this number continues to rise. ${ }^{1}$ Many studies have explored the situation-specific needs, concerns, and experiences of family caregivers of people with different types of chronic illnesses, such as Alzheimer's disease, other forms of dementia, or cancer. This extensive work has resulted in a voluminous literature about caregiving.

Although some caregivers have found the tasks, roles, and responsibilities they experience to be intensely burdensome, others have described the experience as profoundly meaningful and positive. ${ }^{2-7}$ Only recently, however, have re-

\footnotetext{
${ }^{1}$ School of Social Work, University of Buffalo, Buffalo, New York.

${ }^{2}$ School of Social Work, University of Wisconsin, Madison, Wisconsin.

${ }^{3}$ The Center for Hospice and Palliative Care, Buffalo, New York.
} 
searchers begun to focus on understanding the unique experiences of family members who care for terminally ill people who are approaching the end of life. Family caregivers are most often frontline care providers for patients enrolled in hospice and palliative care programs.$^{8-9}$ While providing the 24-hour care that becomes necessary near the time of death, caregivers commonly receive information and emotional support from professionals who are providing medical care to the terminally ill person. ${ }^{10}$ Palliative care teams rely on caregivers to assess and report pain symptoms and to administer medications. ${ }^{11-12}$ How family caregivers respond to the intense experiences that accompany caring for someone who is dying, together with how their needs for education, in-home assistance, respite, and emotional support are met profoundly influence the dying person's quality of care. ${ }^{13-17}$

Essential precepts of palliative care dictate that the needs of family and other informal caregivers should be addressed by professionals who can help them understand the dying process and prepare them to provide care that minimizes patients' pain and maximizes their comfort and dignity. ${ }^{18-20}$ Previous research has demonstrated that family caregivers experience emotional, financial, and physical burdens and need help "with coordinating medical and in-home services. ${ }^{5,7,21-25}$ Caregivers simultaneously respond to the patient's increasing dependence and needs for hands-on care while facing the emotional challenges associated with loss and approaching death. Calls for resource development and education of palliative care nurses ${ }^{26}$ social workers, ${ }^{27}$ and physicians ${ }^{28}$ have stressed the need for enhanced training in the provision of support and interventions for family caregivers. To summarize, optimal care of the dying is determined, to some extent, by family caregivers and should address strategies to help them in their role. Understanding the unique aspects of end-stage caregiving becomes essential to that effort.

The present study had two primary aims. First, we sought to understand how caregivers make the transition to end-stage caregiving, a role uniquely different from a more general conception of the caregiving role. This line of inquiry not only may enhance theoretical conceptualizations of the transitions within the caregiving career, but may also have implications for hospice and palliative care programs. Our second aim was to illuminate our understanding of unique aspects of end-stage caregiving using a stress process model. There is reason to believe that, given the intensity of care needs and the emotional challenges of imminent death, end-stage caregiving may present unique stressors, challenges, and outcomes. Understanding the uniqueness of the end-stage caregiving experience may enhance the development of interventions to support these caregivers.

\section{Conceptual framework: family caregiving career}

Pearlin and colleagues were the first to conceptualize caregiving as a career that encompasses three stages and represents major commonalities in the caregiving experience. ${ }^{29-32}$ The three essential stages of caregiving are (1) role acquisition, which is often an insidious process precipitated by onset of the illness and the care recipient's needs; (2) role enactment, which traditionally has been viewed as performance of role-related tasks within the home or in an institutional setting (e.g., a nursing home); and (3) role disengagement, which follows death and typically involves bereavement and recovery. According to this model,

Each stage of caregiving presents distinctive sources of stress; offers some strategies for addressing these difficulties, at the same time as it precludes alternative options; utilizes various personal, social, and economic coping resources, while depleting others; and shapes the choices available in ensuing stages. $^{31}$

An important concept within the caregiving career model involves the transitions that occur from one stage of caregiving to another and the transitional events that may occur within each stage. ${ }^{31}$ Research on the experiences of family members caring for an older adult with cognitive or physical impairments has produced the most empirical data about these transitional events: (1) onset of the illness, precipitating the start of care in the role-acquisition stage, ${ }^{, 32-35}$ (2) nursing home admission, precipitating institutional care in the role-enactment phase ${ }^{35-40}$; and (3) the patient's death, precipitating bereavement in the role disengagement stage. ${ }^{37,39,41-43}$ Because these transitional events occurring between and within stages represent periods of rapid change, they are particularly challenging and important to under- 
stand. This research has led to the development of interventions designed to provide optimal support to caregivers who are going through the transitions of the caregiving career; transitions occur both during and between stages.

It is within the role-enactment stage that most caregivers are likely to interact with and seek support from health care and social service providers. Although previous studies have explored the predictors of the transition to nursing home placement, little is known about other transitions in the role-enactment phase, such as the transition to end-stage caregiving. Three earlier studies focused on the experiences of family members caring for people at the end of life and made some reference to transitions in caregiving; however, all three involved extremely small sample sizes and discussed the transition to becoming a caregiver only in a general sense. ${ }^{4-46}$

\section{Theoretical framework: The stress process model}

The most popular theoretical frameworks applied in earlier investigations of family caregiving at other phases of the caregiving career have been derivatives of stress process models. ${ }^{47}$ For example, Kinsella and colleagues ${ }^{48}$ suggested that application of this model to the study of end-stage caregiving presents several conceptual, methodological, and practical advantages and urged palliative care researchers to adopt this framework. The stress process model developed by Pearlin and associates ${ }^{31,49}$ identified four major components in caregivers' experiences: primary stressors, secondary stressors, resources available to moderate caregiving stress, and outcomes. Because we investigated these components among end-stage caregivers, a brief description of each component is presented next.

Primary Stressors. Stressors are the conditions, experiences, and activities that are problematic for caregivers and are directly related to the enterprise of providing care. ${ }^{31}$ Traditionally, primary caregiving stressors have been conceptualized as the care recipient's symptoms or impairments (functional, behavioral, and cognitive) and the actual caregiving tasks required as a result. The tasks may vary at different phases of end-stage caregiving. ${ }^{31}$ In an exploratory study, $\mathrm{Hull}^{50}$ found that the patient's symptoms, interactions with others, and concerns about his or her own well-being were the sources of stress for hospice caregivers.

Secondary Stressors. Secondary stressors are the ways that primary stressors influence and disrupt other areas of the caregiver's life; they are variable and uniquely individual. ${ }^{51}$ These stresses are the difficulties that may flow from caregiving to other domains of life, but do not entail the provision of care directly. Few studies have sought to identify the secondary stressors of end-stage caregiving. However, some studies have documented economic strains, ${ }^{52}$ life-style interference, ${ }^{53}$ and impacts on the family that are secondary stressors for caregivers of people who are terminally ill. The impact on employment also may be a secondary stressor in end-stage caregiving. ${ }^{31}$

Resources. There is tremendous variability in the outcomes caregivers experience, even when the demands of care are similar. Pearlin and colleagues ${ }^{49}$ proposed that the social, financial, and internal resources available to manage stressful experiences moderate the relationship between stressors and outcomes and help to explain this variability. In a study involving a small number of family caregivers in a hospice service, Hull ${ }^{53}$ identified coping and social support as essential resources used to manage stress. Brinson ${ }^{54}$ interviewed six hospice family caregivers and identified coping strategies of support, adaptive activities, spiritual means, and avoidance. In their review, Kramer and Vitaliano ${ }^{47}$ found that coping and social support were the most widely studied resources identified in the general caregiving literature. However, other resources that end-stage caregivers can draw on to cope with stress have not been adequately explored.

Outcomes. The stressors involved in providing care to a terminally ill family member have an effect on family caregivers' systemic and mental health, as well as on their overall well-being, and often have long-lasting effects. Kramer ${ }^{4}$ documented both positive and negative outcomes among caregivers of older adults with cognitive and physical impairments. A few exploratory studies have identified negative ${ }^{44}$ and positive outcomes $^{55}$ among caregivers of people with a potentially life limiting illness. Other studies have explored how such factors as income, educational attainment, caregiving tasks, ${ }^{22,56}$ and characteristics of the illness ${ }^{24}$ predict psychological and 
physical well-being and emotional distress among caregivers of cancer patients.

During our exploration of the components of the stress process model in end-stage caregiving, the analytic process was guided by the following general questions: What contextual variables have bearing on end-stage caregiving? Are there primary or secondary stressors that are unique to end-stage caregiving? Are there interpersonal resources that end-stage caregivers find particularly helpful to them in their caregiving roles? What are the outcomes experienced by end-stage caregivers?

\section{METHODS}

\section{Procedure}

The study used qualitative methods to explore end-stage caregiving and to provide rich, wellgrounded descriptions of the transitions in participants' own words. In-depth qualitative methods are often used to explore unknown or understudied phenomenon and to promote the development of conceptual and theoretical frameworks. The themes that emerge from qualitative studies are often used to develop quantitative measures that realistically reflect and assess important variables for study.

We used hospice admission to identify family caregivers of terminally ill patients. Patients are eligible for admission to hospice when a physician has determined that their medical condition cannot be cured and will result in death within 6 months. ${ }^{57}$ However, because there is great variance in patient-physician discussions about the end of life ${ }^{58}$ and because these conversations often occur amid other significant medical events, the patient's and family's awareness of approaching death can be highly variable and may change over time. ${ }^{59}$ To ensure that participation in the study would not become a catalyst for changing caregivers' perceptions of the situation and to understand their transition into end-stage caregiving more fully, the words "very or seriously ill" were used instead of "terminally ill" throughout the study. In addition, because many hospice patients are unstable and have rapidly fluctuating symptoms, ${ }^{57}$ a detailed recruitment protocol was developed to identify caregivers of family members who were terminally ill but not imminently dying. The rationale for this protocol was to avoid causing interference during this final and sometimes tenuous stage of life.

Recruitment. A letter describing the study was included in the home care admissions packets of the participating hospice from May 2000 through January 2001. The caregiver, defined as the person listed as the patient's primary caregiver on the patient's hospice admission document, was contacted only if the patient was aged 50 years or older and had a score of 40 to 50 on the Palliative Performance Scale (PPS). ${ }^{60}$ The PPS is a 100-point scale that is used to assess a person's functional decline. A score of 40 to 50 indicates that a person has extensive disease, is mainly bedbound, is unable to work, requires considerable assistance with self-care, has reduced food intake, and demonstrates a level of consciousness that may fluctuate from clear to confused or drowsy. PPS scores of less than 30 may indicate that the final decline has begun.

Caregivers were contacted by telephone to explain the study and, if the patient was still at home after 2 weeks of hospice care, to invite them to participate in the study. The marker of a 2week length of stay at home was used to ensure that contact about the study did not interfere with the initial visits of hospice team members or with important final family times with patients whose length of stay was short and included only the patient's final decline. Appointments were made at a time and place selected by the caregivers and were confirmed by telephone on the day of the interview. Participants received a $\$ 15$ supermarket gift certificate as thanks for their contribution.

Interviews. Semistructured in-depth interviews were conducted with caregivers using an interview guide designed to obtain the following information : history of the patient's illness, experiences with health care professionals and organizations, transition to caregiving, caregiving stressors, resources, family relationships, and experiences with end-of-life care. Interview questions included the following: "It would be helpful for me to understand the history of your family member's illness. Can you please tell me how your family member became ill?" "How was hospice admission presented to you and your family member?" "Please help me understand your experiences as a caregiver; what has it been like for you?" and "How has caregiving changed your relationship with [the family 
member]?" The order of the questions was not standardized.

The interviews always began with a discussion of the patient's medical history, but because each story was different, participants sometimes moved naturally to a discussion of other domains in a different sequence. Probing questions were used to explore each domain fully. The interviews lasted between 1 and $2^{1 / 2}$ hours and were conducted by one of three social workers, each of whom had prior experience in health care, but was not a hospice employee. The interviews continued until the point of theoretical saturation was reached or when no new concepts emerged. During the course of the interviews, the interviewers incorporated constant comparative analysis by validating and confirming participants' descriptions and meaning against concepts that had emerged from previous participants.

Analysis. Interviews were tape recorded, transcribed, and entered into Non-numerical Unstructured Data Indexing, Structuring and Theorizing (NUD*IST) software. The first step of data analysis included organizing and coding textual data by relocating corresponding sections from each transcript under categories that were named for the domains of the interview schedule (e.g., transition to end-stage caregiving, changes in relationship) to facilitate within-group analysis.

Next, the data were examined and coded using concepts from the stress process model: primary and secondary stressors, resources, and outcomes. ${ }^{32}$ The transcripts were reviewed further to understand the transition to end-stage caregiving and to enumerate its unique tasks. First, axial codes were created, and related sections of text were moved to headings, such as "Tasks" and "Transitions." 61 Multiple iterations of coding and constant comparative analysis were used to extract descriptors of how the transition occurred. ${ }^{62}$

The issue of representativeness, or the extent to which results can be generalized to other situations, is approached in qualitative research by using strategies for rigor ${ }^{63}$ : the degree to which a qualitative study's findings are authentic and their interpretations are credible. There are several methods of establishing rigor ${ }^{63}$; we used observer triangulation, the independent coding of transcripts by two coders, and established an audit trail consisting of written documentation of how the themes were developed. ${ }^{62,63}$ The themes were established by examining coded excerpts and grouping them under organizing concepts. Each theme (e.g., near-acute care) was developed to represent accurately a group of coded excerpts that had convergent meaning. Ultimately, a matrix of the components of end-stage caregiving with the stress process model emerged.

\section{RESULTS}

\section{Sample}

Interviews were conducted with 74 family caregivers of hospice patients aged 54 to 88 years $(\mathrm{M}=74$ years) whose diagnoses at hospice admission were primarily cancer $(81 \%)$. All recipients of care had been determined to have a prognosis of 6 months or less and had received at least 2 weeks of hospice care. The patients with cancer had either completed or refused treatment.

The caregivers' ages ranged from 21 to 87 years $(\mathrm{M}=56$ years); 50 were women $(68 \%)$ and 24 were men $(32 \%)$. Forty-six percent of the caregivers were spouses (23 wives and 11 husbands) and 49\% were adult children (23 daughters, 11 sons, 2 daughters-in-law). The remaining $5 \%$ were 2 siblings and 1 grandchild. Sixty-eight caregivers were Caucasian (92\%), 5 were African American, and 1 was Hispanic. Forty-six percent were Catholic, 31\% were Protestant, and 3\% were Jewish. The religious affiliations of the remaining $20 \%$ were classified as Other, Not active, or None.

\section{Transition to end-stage caregiving}

Determining when a patient enters the endstage of a terminal illness can be difficult, not only for people and family members, but for physicians as well. The study results revealed that end-stage caregiving was characterized by the following four elements: (1) comprehension of terminality, (2) near-acute care, (3) executive functioning, and (4) final decision making. Figure 1 illustrates the progression to end-stage care.

Comprehension of Terminality. A central emergent theme that was evident in the interviews with all caregivers was the recognition that the family member was dying. We selected the term comprehension of terminality to describe a new state of awareness that death would be the inevitable outcome of the illness. This conceptualization was based on the influential work of Glaser and 


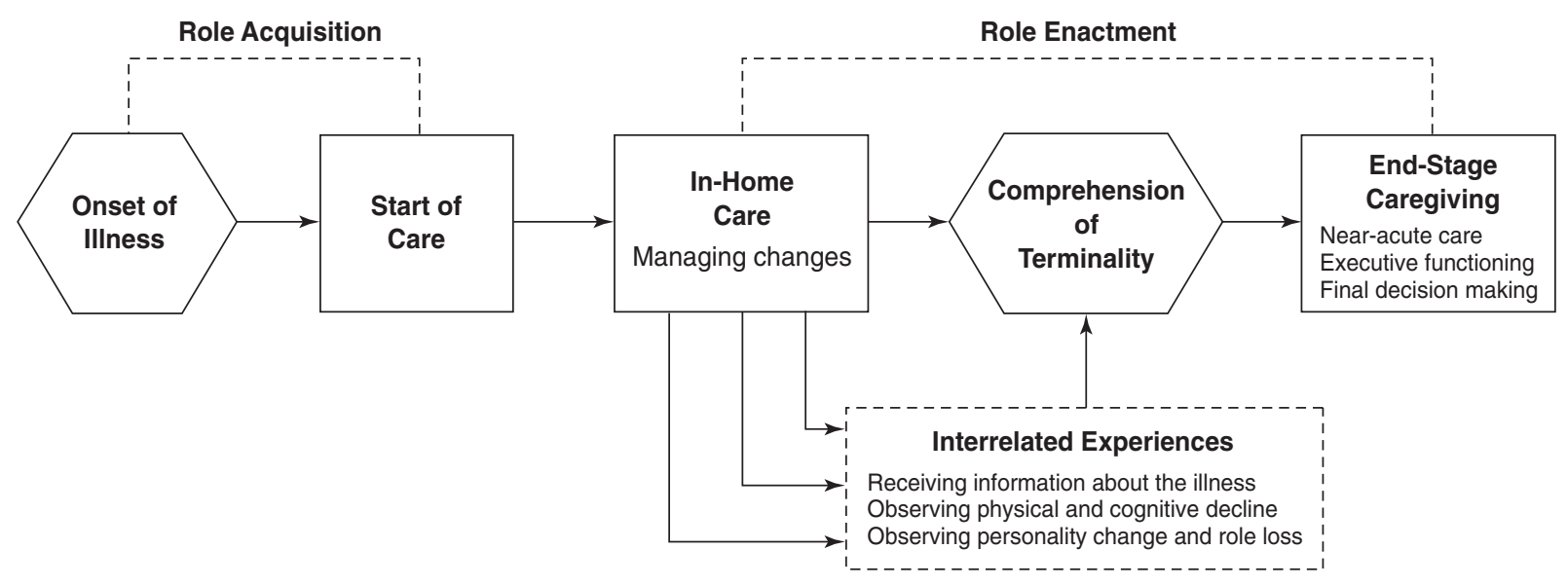

FIG. 1. Progression of End-Stage Caregiving.

Strauss, 59 who described five "awareness contexts of dying": open, closed, suspicious, discounting, or mutual pretense. Each context reflects a distinctly different type of shared understanding about the patient's condition. The caregivers' comprehension of terminality was clear-cut: They entered this state of awareness when they recognized that death was unmistakably approaching. Their comprehension was influenced by interaction with the patient (sometimes including the patient's reflections on dying), others in the informal support system and health care providers. Comprehension emerged from three interrelated experiences: (1) receiving and assimilating information about the diagnosis, prognosis, and progression of the illness, (2) observing progression of the disease as it was manifested in the patient's physical, behavioral, and cognitive changes, and (3) observing the patient's personality change and role loss.

Although it may seem that hospice admission would precipitate the comprehension of terminality, some participants did not grasp the imminence of death fully until after the hospice team was in place and had begun providing end-of-life care and information about the dying process. In other words, the patient's admission to hospice was not necessarily the factor that hastened all caregivers' comprehension.

Receiving Information About the Illness. Information about the patient's diagnosis and prognosis and the expected progression of the disease came from several sources: formal care providers, such as physicians, social workers, and other health care professionals; informal sources of support, such as family members who were medical professionals or had been through similar caregiving experiences; and textual sources, such as libraries and the Internet. Although communication between caregivers and physicians was an important and primary source of information, the quality of these interactions was highly variable: physicians' willingness to spend time and attention on explaining details to ensure family members' comprehension ranged from "wonderful" to "minimal." Thus, the information they provided was often supplemented by family members' contact with office personnel, hospice nurses, and social workers, who provided more detailed explanations and offered additional suggestions and resources. However, interactions with formal care providers also were influenced by the family's receptivity to hearing bad news. As one caregiver said,

I wanted to know where we were going with this, and I listened to every word for a clue as to-was he [the physician] going to say this was terminal? Give us a timeline? Was he going to ... probably mention another treatment or option? "We're gonna treat the pain and control the symptoms for how long it takes" was the end of the sentence. It was an afterthought that [he said] 6 to 9 months ...., and then even more softly "Er, 4 to 6 . . . ." I could easily have missed this if I wasn't listening for it. I realized as I listened to him tell this to the kids that he'd probably told me this before and I hadn't gotten it. 
Caregivers' conversations with friends or relatives also yielded important information. Friends or relatives who had been caregivers for a dying loved one provided important information and practical suggestions. Those who were health care professionals were able to describe sometimes complex medical concepts in more understandable terms. One caregiver described how a family member provided this support when she said, "My sister-in-law worked at [a cancer hospital] for 8 years; she was our rock." Participants sought information about the patient's illness from multiple sources, and they grasped the realities through these conversations. A daughter-caregiver's words illustrated this:

I came home and called my friend, a nurse practitioner. She said, "Do you want me to tell you about it [pancreatic cancer]." At first, I said no. Then I said, "Yes, I need to know; I know it is bad." She started reading off the symptoms; I've never lived such a bad half-hour in my life! There's just no hope here! I mean you really just passed a death sentence. You go from Mom is sick to Mom is dying, Mom is leaving us. It's a lot to take in in a short time, you know? I didn't know how bad it was gonna be.

Observing Physical Decline. Caregivers' comprehension of terminality also included observations of medical events or diagnostics, intensifying symptoms, and behavioral or cognitive changes. For some caregivers, a sudden and dramatic medical event, such as a blood-soaked pillow, a seizure, or a confirmatory $\mathrm{X}$ ray or CT scan, revealed that the condition had become life limiting and provided visual cues that enhanced comprehension. For others, the increasing influence of intensifying multiple symptoms, such as pain, nausea, anorexia, falls, jaundice, abdominal distention, weight loss, fatigue, and weakness, became unmistakable. As one caregiver remarked, "Her body was beginning to deteriorate." Another caregiver said,

Everything's changing. [My mother] . . . seems to be shrinking at an incredible rate, and her whole face is changing. Her skin is sliding around a lot, but they measure her belly to see how the tumor is growing. I realized just the other day that all of my mem- ories of her somehow show in the pictures.

She doesn't look like she did at all.

Behavioral changes, particularly with regard to eating, were often telltale signs for families: "He couldn't eat and kept getting weaker" and "We noticed that he was going from solid foods to softer foods." Other behavioral cues included obvious withdrawal from favorite activities, the appearance of confusion, a flat affect, or wandering behaviors. One caregiver remarked, "She stopped watching TV. To me that was a sign."

Physical and cognitive decline triggered the need for family members to provide additional indirect care, further advancing the caregiver's awareness that death was approaching. A patient's son illustrated this awareness as follows: "On practical matters [car maintenance], as I talk she listens to my voice, and when I get done, she says, 'Do what you think is best.' She's letting go."

Observing Personality Change and Role Loss. Caregivers' comprehension of death's inevitability became clearer as they witnessed changes in the patient's personality and family roles. They described how their loved one's personality began "slipping away." As the intensifying disease process began to wash away the patient's salient personality features, it also affected his or her ability to fulfill spousal or parental roles, which became a daily reminder of the approaching death. In the words of three caregivers:

I feel I've lost him a long time ago.

I can't read my own husband anymore, and we've been married for 45 years. I don't know if he's anxious or having pain.

She's not herself anymore; she would have enthusiastically helped me with this project.

Caregivers commingled past, present, and future, intertwining memories, current losses, and visualization of the future without the loved one. This process made their comprehension grow clearer, and their sense of loss over the person's identity was sharp and powerful. A daughter watched her father, who had always been in robust physical condition, during one of these difficult moments: "It was real hard for me to watch my dad begging for pain meds in the hospital. The hardest thing for me was to see him giving up." 
Because comprehension of death's inevitability emerges from understanding information about the illness, observing the loved one's physical and behavioral decline, and interacting with the dying loved one, it takes time to acquire. When it happens, however, everything else takes on a new perspective.

End-stage caregiving and the stress process model

Background and Context. Individual and family demographic characteristics, the onset of a patient's illness, and its trajectory shaped the context in which caregivers moved from early middle to end-stage caregiving. In some situations, the onset of the symptoms and the diagnosis were sudden and dramatic, occurring "out of the blue." In other situations, the symptoms developed gradually and the person had been through many earlier phases of treatment and remission. Some family caregivers had begun caring for the loved one many years earlier and had weathered many illness-related crises. The trajectory of each patient's illness was individual and varied. In some situations, the patient denied the seriousness of encroaching symptoms. For example, one caregiver expressed her nagging feeling about the onset of her husband's illness:

All this time, he kept saying, "It's gas." I knew it wasn't gas. I knew he was getting pale. I could see the look on his face. I tried to explain to him so many times that you don't say "It's gas" when it's pain. He finally admitted to the pain.

Figure 2 illustrates a conceptual model that captures the essential themes that were identified within the framework of the stress process model as salient to the experience of end-stage caregivers.

Primary Stressors. Three primary stressors that are unique to end-stage care are: near-acute care, executive functioning, and final decision making.

The term near-acute care characterizes the intense management required during the patient's physical decline during the final stage of a terminal illness. It encompasses hands-on care that begins during earlier stages of the illness (e.g., managing the patient's medications, assisting with ambulation and transfers from bed to chair) and is similar to the care provided for patients with nonterminal illnesses (e.g., assessing safety risks, such as potential falls, getting to the bathroom, using stairs, unsupervised smoking). In end-stage caregiving, however, the hands-on care required expands to include hygiene, bathing, toileting, massage, and dressing and indirect care such as cooking, cleaning, bill paying, managing medical paperwork, banking, shopping, and running errands.

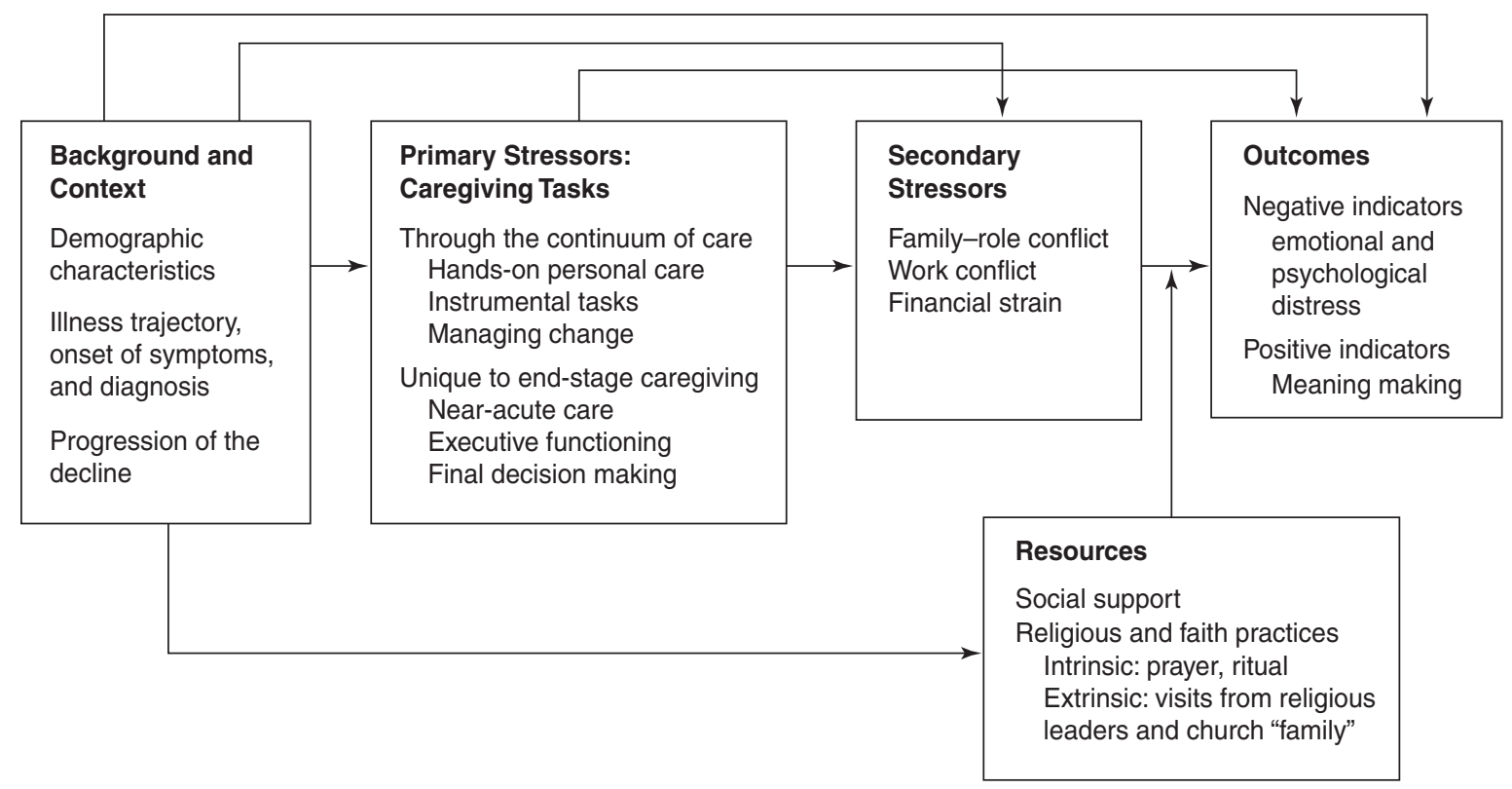

FIG. 2. Stress Process Model and End-Stage Caregiving. 
In near-acute care at the end of life, however, these tasks become intensified because the caregiver must manage multiple simultaneous needs that often fluctuate rapidly and are dramatic and distressing. Specific changes that characterize the dying process and require near-acute care include some combination of uncontrolled pain, nausea, delirium, hallucinations, confusion, restlessness, anxiety, diminished food intake, and incontinence.

Maximizing the terminally ill patient's comfort while minimizing his or her distress was a challenge that many caregivers felt unprepared to handle. However, caregivers can be providing near-acute care because the patient's condition warrants it, yet be unaware that death is imminent.

The term executive functioning was selected to represent how the caregiver upheld patient's wishes and carried out decisions that eased the patient's physical comfort and relieved contextual stressors, such as paying bills and making purchases, while enabling the patient to continue making decisions when possible. As dying patients lost the wherewithal to manage their affairs, their caregivers began to take charge and fulfill an executive function.

Executive functioning differed from the absolute authority that accompanies the roles of a health care proxy or power of attorney because it was invoked only when fatigue, confusion, or physical limitations made it impossible for patients to manage their affairs. As the patient's abilities faded, the caregiver made certain that bills were paid and managed the situation to ensure the patient's physical comfort and relief from environmental stress. One participant illustrated assumption of the executive function as follows:

I told her, "I'm going to sell the old car and put the money into the house account"; we agreed. We discuss practical matters or I talk with her, but it's getting more and more to where she listens for the sharing. She listens to hear my voice and then, when I get done with the explanation, it's always "What ever you think is best. Do what you think is best."

While functioning as the executive, caregivers asked patients, family members, and physicians pointed and sometimes leading questions about treatment or symptom management. As one participant said while caring for her father, who was dying of heart disease, "I'll be honest with you; my father wouldn't be alive today if it wasn't for all the questions I asked his doctors because we wouldn't know. Our background isn't in health care."

Caregivers also facilitated exchanges of information and often became the messenger of information to family members who were involved only peripherally, either because they lived out of town or did not become involved. Functioning as an executive also included negotiating assistance with and for the patient and often involved organizing 24-hour care. In addition, caregivers facilitated secondary support by answering telephone calls and mail and by arranging visits and contacts with important friends and relatives.

The term final decision making refers to tasks required when caregivers recognized that time was slipping away. Thus, they had to initiate discussions with the patient about the end points of care (dialing 911 or rehospitalization) and, in some instances, urge the patient to complete an advance directive or a health care proxy. Decisions also had to be made regarding the most appropriate place for the funeral and selecting music, readings, and burial clothing. In some situations, caregivers helped patients carry out their wishes concerning a party or project or arranged for the patient to complete financial arrangements, such as writing a will or selecting insurance beneficiaries. When necessary, caregivers made appointments for an attorney or an insurance agent to come to the patient's home to complete necessary business transactions. One participant illustrated the stress associated with final decision making as follows:

It's been tough going through all of these things, and I've really had to push to get everything done. We need to do the stuff so I can take care of his bills. I need to be put on the checking account; he needs to show me how to do those things with Medicare. We need to talk about how he wants it in the end. I don't have a clue about cremation or about planning a funeral. I have to go to the funeral home and pick out an urn.

Secondary Stressors. The secondary stressors that participants faced were family and role conflicts, work conflicts, and financial strain. The family responsibilities that participants faced were similar to the responsibilities of people who 
provide care to patients with nonterminal illnesses: the sometimes conflicting needs of children, spouses, grandchildren, or another ill relative. Family and role conflicts were especially stressful when the dying patient's intensifying needs required round the clock care. A participant juggling the needs of multiple family members and a job illustrated how these stressors were intensified when her father's condition entered the end stage and she moved into his house to reduce the chaos:

My father had custody of my niece, who has all kinds of behavior problems. I became involved in her care as he got sicker. I decided to give up my job and move in with my dad. I'd been living between my house and his because he was too weak to stay alone.

All the employed caregivers faced conflicts because of inflexible work schedules, fear of losing their job, the need for frequent out of town travel, or coworkers who do not understand the demands of caregiving. During the end stage of caregiving, however, the demands of the workplace seem particularly harsh because of the erratic nature of changes patients undergo in the terminal stage of an illness. For example, how long a loved one will need increasing care is, at best, unpredictable and thus difficult to plan for. Caregivers said they had to call their employer repeatedly or leave their job when the patient's situation changed dramatically and they were needed at home. When unforeseen changes occurred, the employed caregivers often felt caught between their responsibilities to the dying family member and to their employer. An insurance salesman who was his mother's caregiver illustrated this type of conflict by saying, "I called my boss and said, 'You know, don't expect much out of me until this ... is all over. ${ }^{\prime \prime}$

Unpaid deductibles or co-payments and the cost of prescription drugs caused financial strain for caregivers throughout the stages of their loved one's illness, and they remained a concern at the end stage of life. As families struggled to provide round the clock care during the end stage, however, the causes of financial strain were compounded. For example, one family's solution involved a family member who had left her job and moved across the country to become a full-time caregiver for her mother, who was ill. "I was making good money, but someone needed to be with her, and I'm the one in the family who could leave. I'll find something else after this is over." As a caregiver, however, she encountered family conflict about who would support her financially while she provided round the clock care. Other participants hired aides to stay with the loved one either for respite or while they were at work

Sometimes work conflict and financial strains overlapped. Mr. P, an only child, divorced father, and full-time employee, illustrated this complex interrelationship:

I have a real high level of responsibility in my job and a lot of people under me. I was promoted; it's a make or break situationthis is something I know how to do. But I work 7 days a week, and it does get a little overwhelming because my dad is so sick and my son is going back to school so I can't count on him being here. I've thought about hiring someone to stay with him because he can't be alone ... , [but] some of these agencies charge . . \$ \$16 an hour, so I'm looking for someone I can afford.

Resources. In end-stage caregiving religious and faith practice involved both intrinsic (intrapersonal) and extrinsic (interpersonal) components. One caregiver described the intrinsic importance of religion to her mother and herself in the following words:

Ultimately, anyone facing death is stripped of everything. No doctor or medicine can help you, no person can help you, and even the person you love most is helpless. So . . . all of a sudden, it is you alone and your maker if you believe in one. I think if you have a strong belief system-and my mother does, she was raised a Catholic - that it helps.

During this difficult time, some caregivers called on the family's priest, minister, rabbi, or elder at the dying person's request. Others depended on a hospice chaplain for extrinsic and social support. One participant described the importance of this extrinsic support for his mother as follows: "Her church has been a big supportthere's a lot of people who visit and bring food. I've realized how important 'church family' is at this time."

Notably, other caregivers depended on family friends who also were religious leaders for com- 
fort and support. In still other situations, religion was decidedly absent, and caregivers indicated that it was neither wanted nor needed. Other differential responses included the rejection of religious involvement or anger at God for allowing the illness to happen. As one participant said, "I've never believed in God and I'm not going to start now."

Social support such as the presence of and comfort from friends and extended family members helped caregivers handle end-stage care. These people provided respite for caregivers by sitting with the loved one while they ran errands and offered important outlets for caregivers to talk about their feelings. An example of important friendship and support was provided by a daughter-caregiver: "I have wonderful friends. One came with us to the doctor when he said Dad had 2 weeks to live. There was nothing they could do. Thank God she was there."

Outcomes. Family members described various forms of emotional and psychological distress that occurred in end-stage caregiving. Participants universally described "getting upset" as the convergence of deep sadness, intense anger, and profound loss and being completely overwhelmed. They described the fierce intensity of these coexistent feelings as an emotional roller coaster, with extreme highs and lows that were unpredictable and disconcerting. Taking care of his mother through a 3-year decline from metastatic ovarian cancer, one caregiver described his overwhelming feelings as follows:

I had what I call a major meltdown. When her kidneys went, I hit overload. She was in the hospital and I was here, and I was trying to work in the yard. And at least three or four or five times during the day, I literally fell to the ground sobbing. I was so overwhelmed.

The wife of a man dying of a brain tumor tearfully described her deep sadness by saying, "My heart hurts." Some participants directed their anger at specific sources, such as a physician or hospital, whereas others experienced more generalized anger at targets, such as smokers or traffic. One wife-caretaker expressed her enduring anger about the poor treatment her husband received by saying, "I'm still very angry by their lack of feeling. I just want to scream; it was uncalled for. It sparks something in me; it angers me to the depths."

Family members described positive theme of meaning making after the recognition that death was approaching. Some caregivers found meaning in the strength they discovered in themselves as they faced the challenges of end-stage care. Others found meaning in renewed and deepened family relationships, as well as in their changed perspectives about themselves, life, and death. One participant described meaning he found in the challenges of end-of-life caregiving: "Sometimes we're given things unexpectedly to meet a situation." Another spoke about how her family has found meaning in providing care for her mother and said, "It's been really hard to get through, but it has brought us closer."

Other participants also described how the experiences of end-stage caregiving were changing them as people and bringing them a new perspective and strength. A daughter described the meaning she had found in her mother's impending death:

She could find the good in anything. I just hope that I can be like her. Honesty, goodness, peacefulness, calm; those are all the adjectives that describe her. And that's why it's going to be so hard. So I keep telling her, "You've given us all those things. And we will remember them, and your spirit is going to keep going, and you can go any time you want because you've given us every gift you know how to give.

In addition, she reflected the spiritual meaning that some caregivers experienced as they provided end-stage care by saying,

It's just that it's never gonna leave me. And I'll continue to talk to her after she's goneyou know, not in the sense of going to a medium and trying to find her, but just . . . talking: "Momma, you know if you were here, this is what I'd be saying to you."

\section{DISCUSSION}

As the results from the semistructured interviews conducted with the family caregivers of 
74 terminally ill older adults pointed out, the transition into end-stage caregiving that accompanies the final phase of a terminal illness depends on the comprehension of terminality. This transitional event emerges from the interrelationship among three factors: (1) the family receives and integrates information from health care providers, friends, and written sources about the diagnosis, (2) the caregiver observes physical changes, such as weight loss and fatigue, and (3) the family observes changes in the person's personality and loss of former roles, telltale signs that death is approaching. The results also revealed three functions that characterize caregivers' entry into end-stage care: the need to provide increasingly more intense, allencompassing care (near-acute care), the need to facilitate or manage decisions that have become difficult for the dying patient to make and carry out (executive function), and the need to ease the patient's concerns by handling business matters, funeral plans, or unresolved issues (final decision making).

Providing care to a terminally ill family member is a physically and emotionally intense experience for caregivers, but it can be a profoundly meaningful experience for them as well. It also is important to note that family caregivers live with the memories of the final stage of the care recipient's life. Thus, greater understanding about the specific stressors and outcomes caregivers experience can guide palliative care professionals as they help families that are navigating the unknown and unforeseen changes related to a family member's approaching death.

Although the participants illuminated our understanding of caregiving tasks that became salient in end-stage caregiving, fluctuations in the course of disease may initiate these functions at other times. For example, executive functioning and final arrangements may become a central focus for family caregivers of people with dementia well before the end stage of caregiving. Final decision making may become necessary when the diagnosis of a critical illness prompts relatives to consider making plans; however, if the symptoms later stabilize, caregivers may focus on new problems that emerge.

The finding that hospice admission can hasten the caregivers' comprehension of terminality illustrates the importance of further studies to understand the predictors, correlates, and outcomes as- sociated with comprehension of terminality in contexts of care other than hospice and with patients who have illnesses other than cancer. It also is important to understand situations in which caregivers do not comprehend terminality. There may be important factors that contribute to the differences between caregivers of terminally ill patients who do comprehend terminality and caregivers who do not, because the lack of such comprehension may create barriers for professionals who attempt to initiate meaningful communication with families about end-of-life care and decisions regarding such matters as Do Not Resuscitate orders and advance directives.

The results of the present study both build on and contribute to the knowledge of end-of-life caregiving. By extending Glaser and Strauss's work ${ }^{59}$ on the awareness of dying, the results further enumerate the individual elements involved in comprehension of terminality. Using and adapting the concepts from the caregiving career ${ }^{31}$ and the stress process model ${ }^{49}$ the results support prior research that found end-of-life caregiving is a stressful and emotionally laden experience, ${ }^{4}$ as well as one that creates many burdens for family caregivers. ${ }^{52}$ In addition, by illuminating the specific stressors associated with providing care to a family member with a terminal illness, the results characterize the highly intense and emotional family climate at the end of life. ${ }^{10,64,65}$ Furthermore, they not only underscore the important function these intense emotions play in preparation for death and anticipated loss, but also contribute to the growing body of knowledge emphasizing the important emotional work involved in end-stage caregiving for families facing a loss. ${ }^{55,56}$

\section{Implications for professional care providers}

The study findings have implications for social service and health care providers. The emergent themes regarding end-stage caregiving tasks suggest that professionals can help to prepare caregivers better for the functions and tasks associated with near-acute care, executive functioning, and final decision making. The findings also suggest that physicians, nurses, and social workers would be well advised to begin their assessment, intervention, and educational activities by understanding the caregiver's perspective concerning the patient's illness and by determining how much information the caregiver wants as the ill- 
ness progresses. Supportive and informative contacts that may help families comprehend terminality involve using visual materials and detailed, concrete explanations; allowing time for family members to process information; and offering suggestions regarding sources of additional information, such as useful Web sites or printed literature.

Professional care providers' awareness of how primary and secondary stressors change as death approaches is an important component of addressing the needs of patients and families as a unit. ${ }^{18}$ In particular, professionals need to prepare caregivers better for the unique tasks associated with end-stage caregiving, for example, by devising organizational strategies for managing the patient's medications, advising caregivers on how to perform the tasks involved in near-acute care, and providing them with guidance about making final arrangements. Such strategies will help caregivers understand the best practices for end-stage care, such as recommendations concerning food and fluid intake and the essentials of symptom management. In addition, professionals can advocate for flexibility in the workplace, use of provisions of the Family Medical Leave Act, and other resources that would support end-stage caregivers. Palliative care professionals can enhance caregivers' well-being, beginning at the role enactment phase after the death and through bereavement, by providing emotional support, information, and encouragement. The present study underscores the need to develop and evaluate the effectiveness of a variety of interventions.

\section{Implications for researchers}

Characterizing and describing the dynamics specific to end-stage caregiving also is important for researchers in the field of palliative care. The themes that emerged from the present qualitative inquiry can be used to develop quantitative measures. Specifically, interviews guided by the themes that emerged during the study would enhance professional care providers' understanding of caregivers' perspectives concerning these dynamics. Using concepts from the stress process framework as a lens through which to view endstage caregiving provides meaningful perspectives on family stress at the end of life. This framework and the study results can guide the development and modification of measures for further study of end-stage caregivers' well-being, assess and test variations in the predictors and moderators of caregiver outcomes, and evaluate the effectiveness of the interventions offered. Further investigation of how various aspects of the stress process model are affected by the timing, duration, and onset of illness among caregivers is needed as well.

\section{Limitations of the study}

The study had several limitations. First, hospice admission was used as a mechanism for identifying the family members of terminally ill adults. Caregivers of individuals who are not eligible for or who lack access to hospice services may have different end-stage experiences that the study did not capture. The results of our study reflect the dynamics of a population that has had interactions with end-of-life professionals in a relatively resource rich environment. Other dynamics involved in end-stage care might emerge during studies with family caregivers who do not interact with hospice professionals. The perspectives of other populations are important to explore and to document the transferability to other populations of the themes developed in the present study. ${ }^{62,63}$ Replicating the study procedures with other populations also would increase the confirmability of our data. ${ }^{63}$

Second, the relatively small percentage of ethnically diverse caregivers in our sample limits the conclusions that can be drawn regarding cultural variation and applicability. Because studies of other populations may document divergent experiences across ethnic groups for many aspects of the stress process model, ${ }^{67-69}$ future studies need to examine the experiences of ethnically diverse populations of end-stage caregiving to understand their needs.

Third, the study had methodological limitations. The cross-sectional design involved only one interview per participant. Longitudinal studies would provide information about how the comprehension of terminality and the stressors found in end-stage care change over time. In addition, because all participants were identified through the same hospice, the transferability of the results is limited. Finally, the use of concepts from the stress process model may limit discovery of other naturally occurring dynamics of a ter- 
minal illness, the end stage of which is highly disruptive and is accompanied by complex emotions that are highly personal and individual.

\section{CONCLUSION}

The concepts from the stress process model helped us explore the domains of end-of-life caregiving and provide detailed descriptions of caregivers' experiences. These concepts are practical and useful for research about specific caregiving situations. The present study heightened our understanding of the demands of endstage care. Nevertheless, we recognize that our study was just one way to understand caregiving. A primary focus on stress does not allow one to appreciate and understand the natural resilience and strength that caregivers bring to the situation. Focusing on the concepts of the stress model may actually limit the depth of description that can be attained when learning from people who are experiencing these lifechanging events.

Considering the needs and concerns of endstage caregivers by using concepts from other theoretical frameworks could lead to important new perspectives. For example, viewing caregiving through the lens of resiliency theory may provide new insights into how family members face and grow through the unforeseen challenges of caring for a dying loved one. ${ }^{70}$ Resilience is the ability to withstand and rebound from disruptive life challenges through a process of adapting to adversity, such as providing end-stage care. Because family members who provide care for their loved ones at the end of life undergo profound change and loss, viewing their experiences from different perspectives can deepen and enhance palliative care professionals' understanding of families' experiences. We encourage future research to focus attention on identifying more clearly the primary stressors that arise at different junctures of the caregiving career and on understanding how to support caregivers most effectively at different stages of that career.

\section{ACKNOWLEDGMENTS}

Supported by a grant from the Margaret L. Wendt Foundation, Buffalo, New York. The authors gratefully acknowledge the reviews of an earlier version, which were provided by Dr. Nancy R. Hooyman and Dr. Deborah K. Padgett. This mentorship was facilitated by the professional network, which has been established through the John A. Hartford Geriatric Faculty Scholars Program.

\section{REFERENCES}

1. Family Caregiver Alliance, National Center on Caregiving: Selected caregiver statistics. Available online at $\langle$ www.caregiver.org/caregiver $\rangle$.

2. Cohen, CA, Colantonio A, Vernich L: Positive aspects of caregiving: rounding out the caregiver experience. Int J Geriatr Psychiatry 2002;17:184-188.

3. Hunt CK: Concepts in caregiver research. J Nurs Scholarship 2003;35(1):27-32.

4. Kramer BJ: Gain in the caregiving experience: Where are we? what next? Gerontologist 1997;37:218-232.

5. Narayn S, Lewis M, Tornatore J, Hepburn, K, Corcoran-Perry S: Subjective responses to caregiving for spouses with dementia. J Gerontol Nurs 2001;27(3): 19-28.

6. Navaie-Waliser, M, Spriggs, A, Feldman, PH: Informal caregiving: Differential experiences by gender. Med Care 2002;40:1249-1259.

7. Pinquart M, Sorenson S: Associations of stressors and uplifts of caregiving with caregiver burden and depressive mood: A meta-analysis. J Gerontol B Psychol Sci Soc Sci 2003;58B(2):112-128.

8. Prigerson HG: Costs to society of family caregiving for patients with end-stage Alzheimer's disease. N Engl J Med 2003;349:1891-1892.

9. Schulz R, Mendelsohn AB, Haley WE, Mahoney D, Allen, RS, Zhang, S, Thompson L, Belle SH: End-oflife care and the effects of bereavement on family caregivers of persons with dementia. N Engl J Med 2003; 349:1936-1942.

10. Powazki RD, Walsh D: Acute care palliative medicine: Psychosocial assessment of patients and primary caregivers. Palliat Med 1999;13:367-374.

11. Lin CC, Wang P, Lai YL, Lin CL, Tsai SL, Chen TT: Identifying attitudinal barriers to family management of cancer pain in palliative care in Taiwan. Palliat Med 2000;14:463-470.

12. Berry PE, Ward SE: Barriers to pain management in hospice: A study of family caregivers. Hospice J 1995;10(4):19-33.

13. Friedman BT, Harwood, MK, Shields M: Barriers and enablers to hospice referrals: An expert overview. J Palliat Med 2002;5:73-84.

14. Johnson CB, Slaninka SC: Barriers to accessing hospice services before a late terminal stage. Death Studies 1999;23:225-238.

15. Kaiser KS: Removing barriers in hospice pain management-A family matter. Caring 1990;9(11):42-49.

16. Murphy EK: Barriers to palliative and supportive care. Nurs Clin North Am 2001;36:843-853. 
17. Prigerson HG: Determinants of hospice utilization among terminally ill geriatric patients. Home Health Care Serv Q 1991;12(4):81-112.

18. AGS Ethics Committee: The care of dying patients: A position statement from the American Geriatrics Society. J Am Geriatr Soc 1995;43:577-578.

19. Cherny NI, Coyle N, Foley, KM: Guidelines in the care of the dying cancer patient. Pain Palliat Care 1996; 10:261-286.

20. Sherman DW: End-of-life care: Challenges and opportunities for health care professionals. Hospice J 1999;14(3/4):109-121.

21. Amirkhanyan A, Wolf DA: Caregiver stress and noncaregiver stress: Exploring the pathways of psychiatric morbidity. Gerontologist 2003;43:817-827.

22. Cameron JI, Franche RL, Cheung AM, Stewart DE: Lifestyle interference and emotional distress in family caregivers of advanced cancer patients. Cancer 2002;94:521-527.

23. Gallicchio L, Siddiqi N, Langenberg P, Baumgarten M: Gender differences in burden and depression among informal caregivers of demented elders in the community. Int J Geriatr Psychiatry 2002;17:154-163.

24. Haley WE, LaMonde LA, Han B, Narramore S, Schonwetter R: Family caregiving in hospice: Effects on psychological and health functioning among spousal caregivers of hospice patients with lung cancer or dementia. Hospice J 2001;15(4):1-18.

25. Hickenbottom SL, Fendrick AM, Kutcher JS, Kabeto MU, Katz SJ, Langa KM: A national study of the quantity and cost of informal caregiving for the elderly with stroke. Neurology 2002;58:1754-1759.

26. A peaceful death: Report from the Robert Wood Johnson Endof-Life Care Roundtable. Washington, DC: American Association of Colleges of Nursing, November 1997.

27. Kramer BJ, Pacourek L, Hovland-Scafe C: Analysis of end-of-life content in social work textbooks. J Soc Work Educ 2003;39:299-320.

28. Billings JA, Block S: Palliative care in undergraduate medical education: status report and future directions. JAMA 1997;278:733-738.

29. Pearlin LI: The careers of caregivers. Gerontologist 1992;32:647.

30. Pearlin LI, Aneshensel CS: Caregiving: The unexpected career. Soc Justice Res 1994;7:373-390.

31. Aneshensel CS, Pearlin, LI, Mullan JT, Zarit SH, Whitlatch, CI: Profiles in Caregiving. New York: Academic Press, 1995.

32. Kramer BJ, Lambert JD: Caregiving as a life course transition among older husbands: A prospective study. Gerontologist 1999;39:658-667.

33. Hirst M: Transitions to informal care in Great Britain during the 1990s. J Epidemiol Community Health 2002;56:579-587.

34. Lawton MP, Moss M, Hoffman C, Perkinson, M: Two transitions in daughter's caregiving careers. Gerontologist 2000;40:437-448.

35. Seltzer MM, Li LW: The dynamics of caregiving: Transitions during a three-year prospective study. Gerontologist 2000;40:165-177.
36. Gaugler JE, Pearlin, LI, Leitsch SA, Davey A: Relinquishing in-home dementia care: Difficulties and perceived helpfulness during the nursing home transition. Am J Alzheimers Dis 2001;16(1):32-42.

37. Grant I, Adler KA, Patterson TL, Dimsdale JE, Ziegler MG, Irwin MR: Health consequences of Alzheimer's caregiving transitions: Effects of placement and bereavement. Psychosom Med 2002;64:477-486.

38. Kramer BJ: Husbands caring for wives with dementia: A longitudinal study of continuity and change. Health Soc Work 2000;25:97-107.

39. Skaff MM, Pearlin LI, Mullan JT: Transitions in the caregiving career: Effects on sense of mastery. Psychol Aging 1996;11:247-257.

40. Zarit SH, Whitlatch CJ: Institutional placement: phases of the transition. Gerontologist 1992;32:665-672.

41. Bass DM, Bowman K: The transition from caregiving to bereavement: The relationship of care-related strain and adjustment to death. Gerontologist 1990;30(1):35-42.

42. Mullan JT: The bereaved caregiver: A prospective study of changes in well-being. Gerontologist 1992;32: 673-683.

43. Schulz R, Beach, SR, Lind B, Martire LM, Zdaniuk B, Hirsch C, Jackson S, Burton L: Involvement in caregiving and adjustment to death of a spouse: Findings from the caregiver health effects study. JAMA 2001; 285:3123-3129.

44. Brown MA, Stetz K: The labor of caregiving: A theoretical model of caregiving during potentially fatal illness. Qualitative Health Res 1999;9:182-197.

45. Wennman-Larsen A, Tishelman C: Advanced home care for cancer patients at the end of life: A qualitative study of hopes and expectations of family caregivers. Scand J Caring Sci 2002;16:240-247.

46. Wilson SA: The family as caregivers: Hospice home care. Fam Community Health 1992;15(2):71-80.

47. Kramer BJ, Vitaliano, PP: Coping: A review of the theoretical frameworks and the measures used among caregivers of individuals with dementia. J Gerontol Soc Work 1994;23:151-174.

48. Kinsella G, Cooper B, Picton C, Murtagh D: A review of the measurement of caregiver and family burden in palliative care. J Palliat Care 1998;14(2):37-45.

49. Pearlin L, Mullan J, Semple S, Skaff M: Caregiving and the stress process: An overview of concepts and their measures. Gerontologist 1990;30:583-594.

50. Hull MM: Sources of stress for hospice caregiving families. Hospice J 1990;6(2):29-54.

51. Zarit SH, Davey A, Edwards AB, Femia EE, Jarrott SE: Family caregiving: Research findings and clinical implications. In: AS Bellack AS, Hersen M, eds. Comprehensive Clinical Psychology. New York: Elsevier Science, 1998:499-523.

52. Emanuel EJ, Fairclough, DL, Slutsman J, Emanuel LL: Understanding economic and other burdens of terminal illness: The experience of patients and their caregivers. Ann Int Med 2000;132:451-459.

53. Hull MM: Coping strategies of family caregivers in hospice homecare. Oncol Nurs Forum 1992;19:1179_ 1187. 
54. Brinson SV: Hospice family caregivers: An experience in coping. Hospice J 2000;15(3):1-12.

55. Enyert G, Burman, ME: A qualitative study of selftranscendence in caregivers of terminally ill patients. Am J Hospice Palliat Care 1999;16:455-462.

56. Nijboer C, Triemstra $M$, Tempelaar R, Mulder $M$, Sanderman R, van den Bos GAM: Patterns of caregiver experiences among partners of cancer patients. Gerontologist 2000;40:738-746.

57. National Hospice and Palliative Care Organization: Hospice Statistics. Available online at 〈www.nhpco.org/i4a/pages/index.cfm?pageid $=3280\rangle, 2001$.

58. Support Principal Investigators: A controlled trial to improve care for seriously ill hospitalized patient: The Study to Understand Prognoses and Preferences for Outcomes and Risks of Treatments (SUPPORT). JAMA 1995;274:1591-1598.

59. Glaser B, Strauss A: Awareness of Dying. New York: Aldine, 1965.

60. Anderson F, Downing GM, Hill J: Palliative performance scale (PPS): A new tool. J Palliat Care 1996; 21(1):5-11.

61. Miles MB, Huberman AM: Qualitative Data Analysis. Thousand Oaks, CA: Sage, 1994.

62. Lincoln YS, Guba EG: Naturalistic Inquiry. Newbury Park, CA: Sage, 1985.

63. Padgett DK: Qualitative Methods in Social Work Research. Thousand Oaks, CA: Sage, 1998.

64. McCorkle R, Pasacreta JV: Enhancing caregiver outcomes in palliative care. Cancer Control 2001;8(1):36-45.
65. Stajduhar KI, Davies B: Death at home: Challenges for families and directions for the future. J Palliat Care 1998;14(3):8-14.

66. McRae H: Managing feelings: Caregiving as emotion work. Res Aging 1998;20(1):137-160.

67. McCallion P, Janicki M, Grant Griffin L: Exploring the impact of culture and acculturation on older families caregiving for persons with developmental disabilities. Fam Relations: Interdisciplinary J Appl Fam Studies 1997;46:347-357.

68. Anderson Dilworth P, Williams IC, Gibson BE: Issues of race, ethnicity, and culture in caregiving research: A 20-year review (1980-2000). Gerontologist 2002;42: 237-272.

69. Connell CM, Gibson GD: Racial, ethnic, and cultural differences in dementia caregiving: Review and analysis. Gerontologist 1997;37:355-364.

70. Walsh F: Family resilience: A framework for clinical practice. Fam Proc 2003;42:1-18.

Address reprint requests to: Deborah P. Waldrop

University of Buffalo School of Social Work

630 Baldy Hall, Box 601058

Buffalo, NY 14260-1050

E-mail: dwaldrop@buffalo.edu 